women with detrusor instability and those with genuine stress incontinence, suggests that future research into aetiological factors of detrusor instability should concentrate on physical, and particularly neurological, aspects.

I Thomas TM, Plymat KR, Blannin J, Meade TW. Prevalence of urinary incontinence. Br.Med J 1980;281:1243-5.

\section{Mortality in patients with bleeding peptic ulcer when those aged 60 or over are operated on early}

\author{
K E Wheatley, J H Snyman, S Brearley, \\ M R B Keighley, P W Dykes
}

\section{Department of \\ Gastroenterology, General \\ Hospital, Birmingham \\ B4 6NH \\ K E Wheatley, FRCS, research registrar \\ J H Snyman, FRCS, research \\ registrar \\ S Brearley, FRCS, research \\ registrar \\ M R B Keighley, FRCS, \\ professor of surgery \\ P W Dykes, FRCP, consultant \\ physician}

Correspondence to: $\mathrm{Dr}$

Dykes.

BrMed f 1990;301:272 not in those under 60 ; we achieved a mortality of $4 \%$ in
2 Wing JK, Cooper JE, Sartorius N. The measurement and classification of psychiatric symptoms. Cambridge: Cambridge University Press, 1974

3 Eysenck HJ, Eysenck SBG. Manual of the Eysenck personality inventory. London: Hodder and Stoughton, 1978.

4 Spielberger $\mathrm{CD}$, Gorsuch RL, Lushene RE. The state-trait anxiety inventory. Palo Alto: Consulting Psychologists Press, 1970.

5 Thomas DG, Davies-Jones GAB, Clarke SJ. Urinary incontinence and minima pyramidal disease. $\mathrm{Br} \mathcal{F}$ Urol 1980;52:460-2.

(Accepted 9 May 1990)
Death from bleeding peptic ulceration is too easily dismissed as inevitable, and death rates of around $10 \%$ indicate unacceptable clinical practice. Endoscopic haemostasis improves results, ' but improvement can be achieved more simply. We reported previously that early surgery improves results in elderly patients but patients over 60 treated with early surgery. ${ }^{2}$ We closed the trial mainly because of the difficulty of holding six surgical firms to a fixed randomisation policy in the face of a considerable difference in mortality in patients aged 60 or over between the two treatment policies being compared ( $4 \%$ with early operation compared with $15 \%$ with delayed operation); this decision was criticised. ${ }^{3}$ We subsequently adopted the policy associated with the lowest mortality, although we no longer regarded the stigmata of recent haemorrhage as an indication for surgery as there is now doubt whether they carry the hazard once thought. ${ }^{+}$We have audited 342 consecutive patients with defined ulcer bleeding over the subsequent five years. We did not exclude patients even if they had severe coincident malignant disease or were moribund; we do not know of a larger study done in a single hospital.

\section{Patients, methods, and results}

We reviewed all patients admitted with upper gastrointestinal bleeding due to proved peptic ulceration from January 1984 to December 1988 (342 patients; 351 admissions). Altogether 214 patients were aged 60 or over. Two hundred and eighteen patients bled from duodenal ulcers or ulcers of the pyloric channel and 124 from gastric ulcers; all were examined by gastroscopy.

Patients were operated on immediately if they had exsanguinating haemorrhage or if a spurting vessel was seen at endoscopy. Patients aged 60 or over were operated on if one episode of rebleeding occurred in hospital, four units of blood or colloid were transfused for initial volume replacement or eight units of blood or colloid were transfused over 48 hours. Younger patients were operated on if two episodes of rebleeding occurred in hospital, eight units of blood or colloid were transfused for initial volume replacement or 12 units of blood or colloid were transfused over 48 hours. Patients were given prophylactic antibiotics and subcutaneous heparin and operated on by experienced surgeons and anaesthetists.

Sixty nine patients fulfilled the criteria for emergency operation, comprising 35 of the 218 with duodenal ulcers and 34 of the 124 with gastric ulcers. Fifty two (24\%) of the 214 patients aged 60 or over were operated on, compared with $17(13 \%)$ of the 128 younger patients. The most common operation for duodenal ulcer was vagotomy and pyloroplasty (21), and the most common operations for gastric ulcer were Billroth I gastrectomy (11) and vagotomy and pyloroplasty with excision of the ulcer (9). In four patients with duodenal ulcer and five with gastric ulcer the only operation was underrunning of the ulcer.

Thirteen patients died from proved haemorrhage of peptic ulcer, a mortality of $4 \%$; the mortality rose with age to $8 \%$ in those aged 80 or over (table). Four of these

Mortality in patients with bleeding duodenal or gastric ulcer according to age

\begin{tabular}{|c|c|c|c|c|c|}
\hline \multirow{2}{*}{$\begin{array}{c}\text { Age } \\
\text { (years) }\end{array}$} & \multicolumn{2}{|c|}{ Site of ulcer } & \multirow{2}{*}{$\begin{array}{c}\text { All } \\
\text { patients }\end{array}$} & \multirow[b]{2}{*}{ Deaths } & \multirow{2}{*}{$\underset{(\%)}{\text { Mortality }}$} \\
\hline & Duodenum & Stomach & & & \\
\hline$<50$ & 59 & 14 & 73 & & \\
\hline $50-59$ & 32 & 23 & 55 & 1 & 2 \\
\hline $60-69$ & 57 & 37 & 94 & 3 & 3 \\
\hline $70-79$ & 45 & 39 & 84 & 6 & 7 \\
\hline$\geqslant 80$ & 25 & 11 & 36 & 3 & 8 \\
\hline Total & 218 & 124 & 342 & 13 & 4 \\
\hline
\end{tabular}

deaths were in patients with advanced malignancy and two were linked with terminal vascular disease; active treatment was withdrawn in all. Two postoperative deaths occurred (operative mortality $3 \%$ ), both in patients with severe coincident disease. Thus in patients not dying from other disease and in whom resuscitation was attempted mortality from bleeding peptic ulcer was $2 \%(7 / 342)$. Contributory factors to death included cardiac failure (two patients), cerebrovascular accident (three), respiratory failure (one), and cardiac arrest at endoscopy (one). Nine operations were done for exsanguinating haemorrhage or spurting vessels, 54 for further haemorrhage, and six when transfusion limits were exceeded.

\section{Comment}

No magical formula exists for reducing the mortality of a disease. In patients with gastrointestinal haemorrhage mortality is low when a logical protocol is adhered to strictly. Our mortality of $4 \%(6 \%$ in patients aged 60 or over) could be achieved in any district general hospital by applying this protocol. ${ }^{5}$ In addition, senior surgeons and anaesthetists should not delegate an operation to inexperienced doctors.

1 Steele RJC. Endoscopic haemostasis for non-variceal upper gastrointestinal haemorrhage. Br f Surg 1989;76:219-25.

2 Morris DL, Hawker PC, Brearley S, Simms M, Dykes PW, Keighley MRB. Optimal timing of operation for bleeding peptic ulcer: prospective randomised trial. Br Med f 1984;288:1277-80.

Langman MJS. Optimal timing of operation for bleeding peptic ulcer. Br Med 1984;288:1761.

4 Garrigues-Gil V, Clamp SE, Morgan AG, Ohmann C, De Dombal FT. Do the stigmata of recent haemorrhage have additional prognostic value in patients with bleeding duodenal ulcer? Scand f Gastroenterol 1988;23 (suppl 144): 59-62.

5 Holman RAE, Davis M, Gough KR, Gartell P, Britton DC, Smith RB. Value of a centralised approach in the management of haematemesis and melaena: experience in a district general hospital. Gut 1990;31:504-8. 